\title{
FOOT ALIGNMENT IN SYMPTOMATIC NATIONAL FOOTBALL LEAGUE (NFL) ATHLETES: A WEIGHTBEARING CT ANALYSIS
}

\author{
ALINHAMENTO DO PÉ EM ATLETAS SINTOMÁTICOS DA NFL: UMA \\ ANÁLISE DE TOMOGRAFIA COMPUTADORIZADA COM CARGA
}

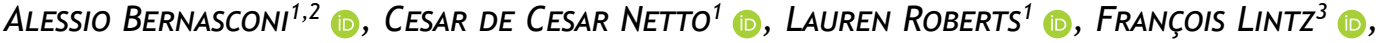 \\ ALEXANDRE LEME GOdOY-SANTOS ${ }^{4}$ (1), MARTIN JOSEPH O'MALLEY ${ }^{1}$ (1)
}

1. Hospital for Special Surgery, Department of Orthopedics, Foot and Ankle Surgery, New York, NY, United States of America.

2. University Federico II of Naples, Department of Public Health, Orthopedics and Traumatology Unit, Napoli, NA, Italy.

3. Clinique de l'Union, Foot and Ankle Surgery Center, Saint-Jean, France.

4. Universidade de São Paulo, Department of Orthopedics, Foot and Ankle Surgery, São Paulo, SP, Brazil.

\section{ABSTRACT}

Objective: Our aim was to describe the foot alignment in National Football League (NFL) players with different symptomatic foot and ankle pathologies using weightbearing cone-beam computed tomography (WBCBCT), comparing them to normally aligned feet as control group. Methods: 41 feet (36 active NFL players) were assessed using WBCBCT and compared to 20 normally aligned controls from a normal population. Measurements included: Foot and Ankle Offset (FAO); Calcaneal Offset (CO); Hindfoot Alignment Angle (HAA); angle between inferior and superior facets of the talus (Inftal-Suptal); angle between inferior facet of the talus and the horizontal/floor (Inftal-Hor); Forefoot Arch Angle (FAA); navicular- and medial cuneiform-to-floor distance. Results: NFL athletes showed a neutrally aligned hindfoot when compared to controls (FAO: 1\% vs $0.5 \%$; CO: $2.3 \mathrm{~mm}$ vs $0.8 \mathrm{~mm}$; HAA: $2.9^{\circ}$ vs $0.8^{\circ}$ in two groups, with all $p>0.05$ ) and a normal morphology of the subtalar joint (no difference in Inftal-Suptal and Inftal-Hor angles). Conversely, in athletes we found a decreased medial longitudinal arch (FAA: $15^{\circ}$ vs $18.3^{\circ}, p=0.03$ ) with smaller navicular (38.2 mm vs $42.2 \mathrm{~mm}$, $p=0.03$ ) and medial cuneiform ( $27 \mathrm{~mm}$ vs $31.3 \mathrm{~mm}, p=0.01)$ mean distances to the floor when compared to controls. Conclusion: In our series, NFL players presented a lower medial longitudinal arch than controls but a neutrally aligned hindfoot. WBCBCT may help shed light on anatomical risk factors for injuries in professional players. Level of Evidence III, Retrospective comparative study.

\section{RESUMO}

Objetivo: Descrever o alinhamento do pé em jogadores da National Football League (NFL) com diferentes patologias sintomáticas do pé e tornozelo usando a tomografia computadorizada de feixe cônico com suporte de peso (weightbearing cone-beam computed tomography - WBCBCT), e comparar as medidas a grupo controle de voluntários com pés de alinhamento normal. Métodos: Quarenta pés (36 jogadores ativos da NFL) foram avaliados usando WBCBCT e comparados com 20 controles da população normal. As medidas incluíram: Offset do pé e tornozelo(FAO); Calcâneo Offset (CO); ângulo de alinhamento do retropé (HAA); ângulo entre as facetas inferior e superior do tálus (Inftal-Suptal); ângulo entre a faceta inferior do tálus e o solo (Inftal-Hor); ângulo do arco do antepé (FAA); distância navicular/solo e cuneiforme medial/solo. Resultados: Atletas da NFL mostraram retropé com alinhamento neutro quando comparados aos controles (FAO: $1 \%$ vs. 0,5\%; CO:2,3mm vs. 0,8 mm; HAA: $2,9^{\circ}$ vs. $0,8^{\circ}$, com todos $p>0,05$ ) e morfologia normal da articulação subtalar (sem diferença nos ângulos Inftal-Suptal e Inftal-Hor). Por outro lado, observamos nos atletas profissionais um arco longitudinal medial diminuído (FAA: $15^{\circ}$ vs. $18,3^{\circ}, p=0,03$ ) com distâncias médias do navicular/solo (38,2 mm vs. 42,2 mm, $p=0,03)$ e do cuneiforme medial/ solo (27 mm vs. 31,3 mm, $p=0,01$ ) menores quando comparados ao grupo controle. Conclusão: Em nossa série, os jogadores da NFL apresentaram um arco longitudinal medial diminuído em relação aos controles, mas um retropé neutro. WBCBCT pode ajudar a esclarecer os fatores de risco anatômicos para lesões em jogadores profissionais de elite. Nível de Evidência III, Estudo retrospectivo comparativo.

Keywords: Foot. Athletes. Tomography.

Descritores: Pé. Altletas. Tomografia.

Citation: Bernasconi A, de Cesar Netto C, Roberts L, Lintz F, Godoy-Santos AL, O'Malley MJ. Foot alignment in symptomatic national football league (NFL) athletes: a weightbearing CT analysis. Acta Ortop Bras. [online]. 2021;29(3):118-123. Available from URL: http://www.scielo.br/aob.

\section{INTRODUCTION}

Professional players who sustain lower extremity injuries may experience a significant reduction in playing time, decrease in performance, and in some cases these injuries can be career ending. ${ }^{1}$ Common sport movements like jumping, running and lateral cutting movements, together with the risk of collision, are associated with a considerable increase risk of injuries - often

All authors declare no potential conflict of interest related to this article.

The study was conducted at the Department of Orthopedics, Foot and Ankle Surgery, Hospital for Special Surgery.

Correspondence: Alessio Bernasconi. Hospital for Special Surgery, 523 East 72nd Street, New York, NY, United States of America, 10023. alebernas@gmail.com 
involving the ankle and the knee. More specifically, foot and ankle injuries accounted for $27 \%$ of total musculoskeletal injuries in competitive professional and collegiate athletes, with $21 \%$ of these injuries resulting in missed play time. ${ }^{2}$ It has also been estimated that $85 \%$ of professional athletes experience at least one ankle sprain during their careers. ${ }^{3}$ In light of these numbers, many studies have and are investigating potential risk and prognostic factors for these elite-level athletes. ${ }^{1,4,5}$ Regarding foot and ankle pathologies, a varus hindfoot alignment in elite athletes has been reported as a predisposing factor for Jones-type metaphyseal-diaphyseal fractures and refractures of the fifth metatarsal. ${ }^{6}$ A possible association between metatarsus adductus and stress fractures of the base of the fourth has also been described. ${ }^{7}$ Furthermore, a high-arched or cavus foot and metatarsus adductus have been proposed as risk factors for Lisfranc injuries and stress fractures of the tarsal bones, respectively. ${ }^{7,8}$

Traditionally, the assessment of foot alignment has relied on conventional radiographic views. Evidence has showed how standard radiographs are inherently limited as they only illustrate the anatomy in a two-dimensional (2D) manner and can be flawed by error from patient and $\mathrm{x}$-ray beam positioning, image superposition and potential measurement errors. ${ }^{9}$ The introduction and increasing use of weight-bearing cone beam computed tomography (WBCBCT) in clinical practice seems to have addressed many of the issues encountered with standard radiographs, allowing a better three-dimensional (3D) assessment of the foot and ankle..$^{10,11}$ WBCBCT obtains images comparable with a traditional CT in quality but does so with the foot in a loaded condition and with a markedly lower radiation dose. Many authors demonstrated the efficacy and reliability of WBCBCT use to measure different foot alignment. ${ }^{10,11}$ Recently, De Cesar Netto et al. investigated foot alignment in National Basketball Association (NBA) players on WBCBCT images, documenting a tendency toward varus hindfoot malalignment. ${ }^{12}$ However, to the best of our knowledge, no study has reported any investigation on National Football League (NFL) players so far.

In this study, we described the foot morphology (measured on WBCBCT images) in a cohort of NFL players that went to our institution with different foot and ankle pathologies and compared them with normally aligned controls. We also discussed our results considering reference data for the same measures performed on normal feet and flatfeet obtained from the most recently available literature.

\section{MATERIALS AND METHODS}

\section{Data collection}

The data used for this study was obtained as part of routine clinical care of NFL players with symptomatic foot and ankle pathologies that underwent WBCBCT as part of their clinical assessment, from September 2013 to November 2017. Institutional review board approval was obtained for the review of these data. The images of 41 feet (17 right, 24 left) from 36 NFL players (mean age 24.9 years, range 16-35) were retrospectively reviewed; a cohort of 20 clinically neutrally aligned feet (gathered from bilateral scans on 10 patients from normal population) was selected as control group. All scans were obtained using a PedCAT ${ }^{\circledR}$ unit (CurveBeam ${ }^{\circledR}$ ) installed in the outpatient clinic of an orthopedic foot and ankle surgery referral center. The datasets were obtained using the following cone beam scanner settings: voxel size, $0.37 \mathrm{~mm}$; field of view diameter, $350 \mathrm{~mm}$; field of view height, $200 \mathrm{~mm}$; exposure time, 9 seconds, total scan time, 54 seconds. The data sets were extracted from the existing database, containing the 3D image data (Figure 1), as well as demographic characteristics regarding age, side, sex, weight, height and the body mass index (BMI).

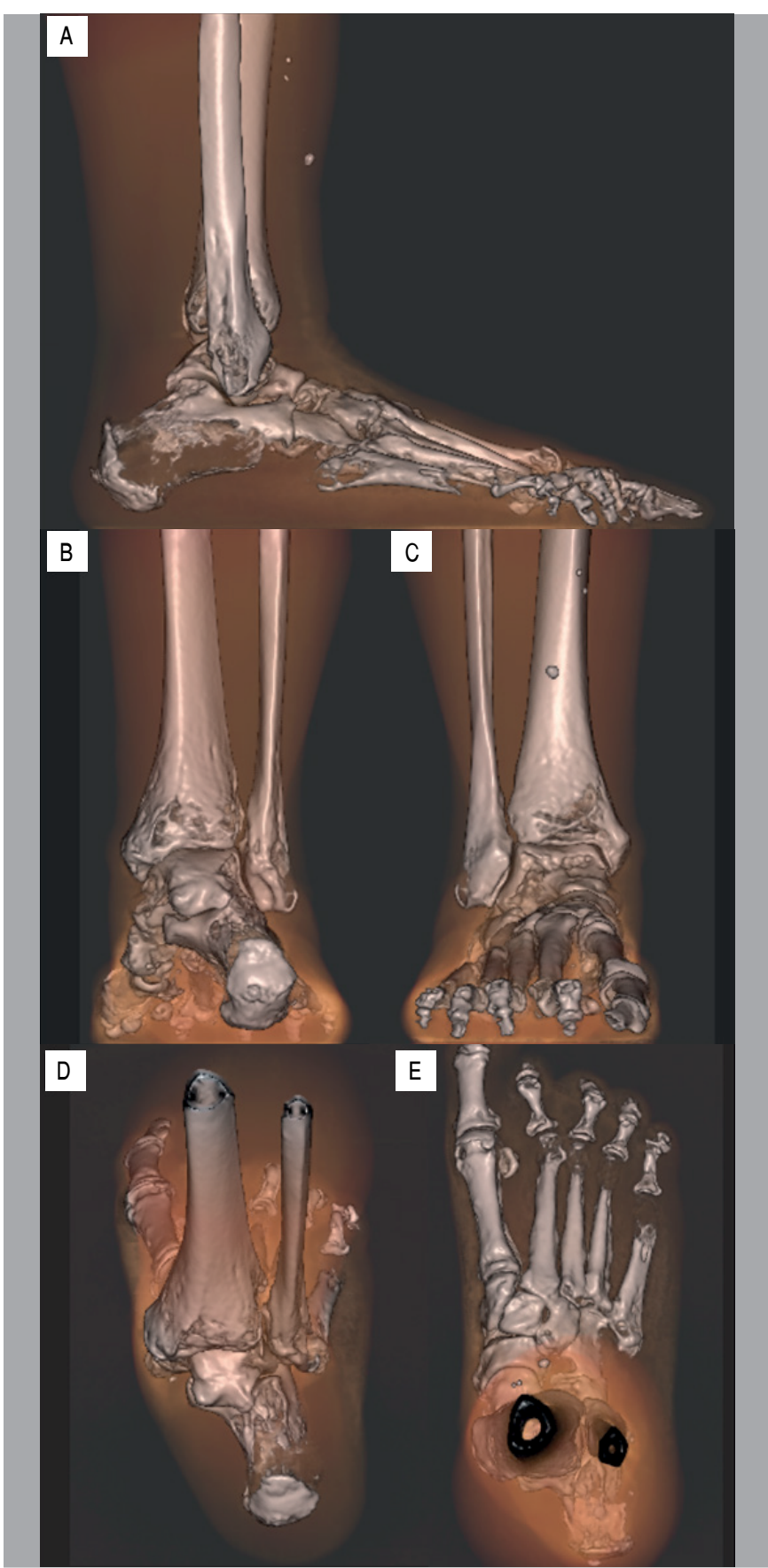

Figure 1. Example of three-dimensional WBCBCT dataset viewed from A) lateral; B) posterior; C) anterior; D) postero-superior; and E) dorsal positions.

\section{Measurements}

For this study, both semiautomatic and manual measurements of foot alignment were performed.

\section{Semiautomatic measurements}

Datasets were screened using the built-in software TALAS ${ }^{\text {тм }}$, CubeView $^{\text {TM }}\left(\right.$ CurveBeam $\left.^{\odot}\right)$, and the 3D coordinates of specific anatomical landmarks required for the software to process and calculate FAO were collected, as described by Lintz et al., ${ }^{10}$ that included the most distal and weightbearing vortex of the head of the first metatarsal, head of the fifth metatarsal and calcaneal tuberosity, as long as the most proximal and central aspect of the talar dome (Figure 2). 

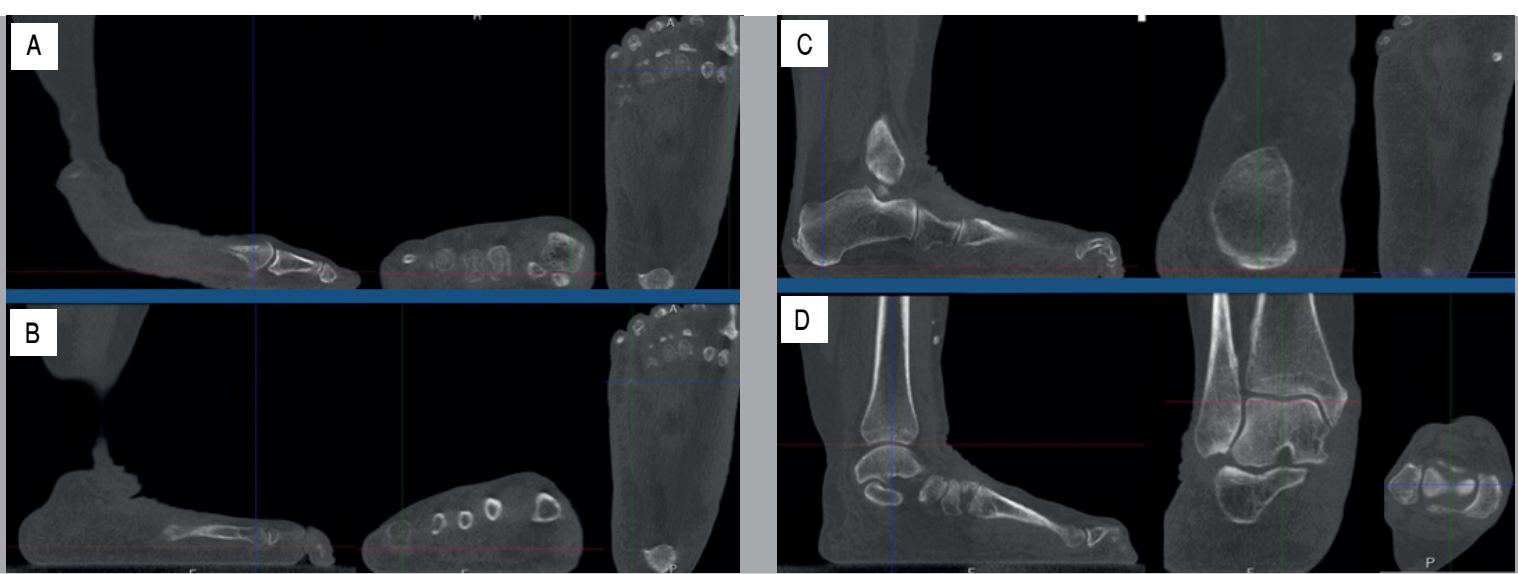

Figure 2. Marking of 3D coordinates of specific anatomical landmarks: A) most distal WB vertex of the head of the first metatarsal; B) most distal WB vertex of the head of the fifth metatarsal; C) most distal WB vertex of the calcaneal tuberosity; D) most proximal and central aspect of the talar dome.

The Foot and Ankle Offset (FAO) was described as a threedimensional measurement of the torque acting in the ankle joint as result of body weight and ground reaction forces. ${ }^{10-12}$ It takes into consideration the relationship between the center of gravity of the foot tripod and the center of the ankle joint, represented by the apex of the talar dome. Negative measurements indicate a varus alignment, where the center of the ankle lies laterally to the bisecting line of the foot tripod. Positive values represent a valgus alignment, with the center of the ankle joint positioned medially to the foot line (Figure 3).

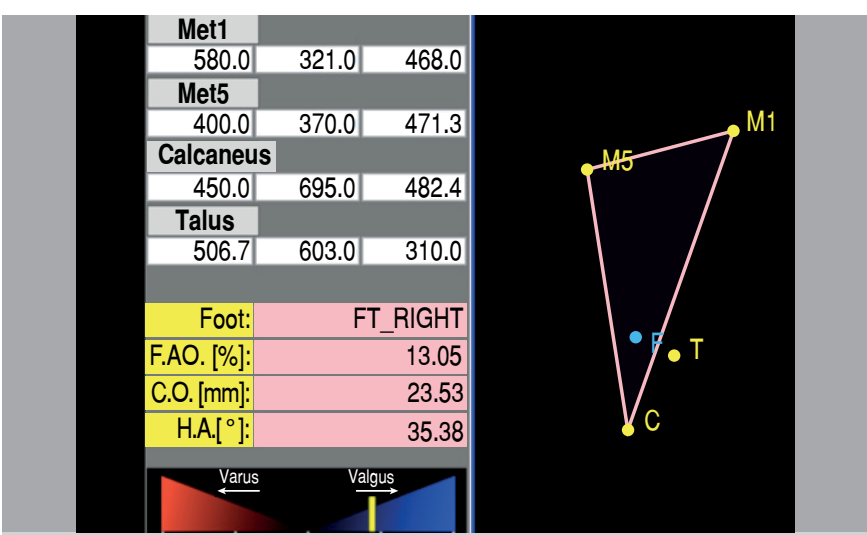

Figure 3. Example of semiautomatic measurement using TALAS ${ }^{\mathrm{TM}}$ CubeView $^{\text {TM }}\left(\right.$ CurveBeam $^{\odot}$ ). Three-dimensional coordinates ( $x, y, z$ planes) were harvested for the first (met1), fifth (met5), calcaneus and talus. The tripod is represented by the triangle formed by the coordinates of M1 (first metatarsal), M5 (fifth metatarsal) and C (Calcaneus). F represents the ideal position of the center of rotation of the ankle joint, that lies on a bisecting line of the tripod. T represents the positioning of the proximal and central aspect of the talus, center of the ankle joint, in this specific patient. It can be noticed that this point is positioned laterally to the $\mathrm{F}$ point, demonstrating an important varus alignment of this hindfoot in this case. F.A.O. is the value for the Foot and Ankle Offset; C.O. represents an estimated value in millimeters that the calcaneus would have to be displaced to correct the alignment of the hindfoot; and H.A. is a two-dimensional representation of the hindfoot alignment angle (reported in the text as HAA).

The mean FAO value in asymptomatic patients with normally aligned foot is described to be at $1.2-2.3 \%,{ }^{10,11}$ and these values were used as a reference for this study. Furthermore, the Calcaneal Offset (CO) and the hindfoot alignment angle (HAA) were recorded. CO represents the distance (in $\mathrm{mm}$ ) between a theoretically neutral position of the calcaneus and the actual position of the calcaneus. HAA represents an estimation of the coronal angular alignment of the hindfoot and it is measured as the angle formed by three points: apex of the center of the talar dome projected on the floor plane (as the vertex), the ideal position of the calcaneus and the actual position of the calcaneus.

\section{Manual measurements}

In the coronal plane, three angles were measured. The first two included the angle between the inferior aspect of the posterior facet of the talus at the subtalar joint and two reference lines: one horizontal line representing the floor (Inftal-Hor) and a tangent line to the superior aspect of the talar dome (Inftal-Suptal). Both angles evaluate the orientation of the subtalar joint. The coronal plane in which the measurements were performed was determined in the sagittal plane at the midpoint of the longitudinal length of the posterior facet of the subtalar joint. For these angles, positive values indicate a valgus alignment and negative values indicate varus alignment.

The third angle measured in the coronal plane was the forefoot arch angle. It measures the transverse arch height of the foot and the relative supination/pronation of the forefoot. Positive values indicate a relatively higher positioning of the medial cuneiform in relation to the fifth metatarsal.

In the sagittal plane, two measurements were recorded, both using the height evaluation of the transverse and longitudinal arches of the foot. The first was the navicular-to-floor distance, measured from the most inferior aspect of the navicular to the floor line. The second was the medial cuneiform-to-floor distance, measured from the most inferior aspect of the medial cuneiform to the floor line. For all manual measurements, standard values based on the most recent literature were gathered and used in the comparison of normally aligned feet, varus and valgus alignment of the hindfoot and flattening or elevation of the arch of foot. ${ }^{13}$

\section{Statistical analysis and synthesis of results}

Data were reported as mean values, percentages, and minimum-maximum values. Normality of data was assessed by the Shapiro-Wilk test. Intergroup differences for demographic characteristics (age, side, height, weight, and BMI) and mean values for measurements were compared with Student's test (normally distributed variables) or Wilcoxon's rank-sum test (non-normally distributed variables). Fisher's exact test was used for categorical variables. Analysis was performed using STATA statistical software package (version 12.0, StataCorp, College Station, TX, 2011). Statistical significance was set at 0.05 ( $p$-value). 


\section{RESULTS}

Demographic data of players and controls are outlined in Table 1.

Table 1. Main characteristics of our sample and control group.

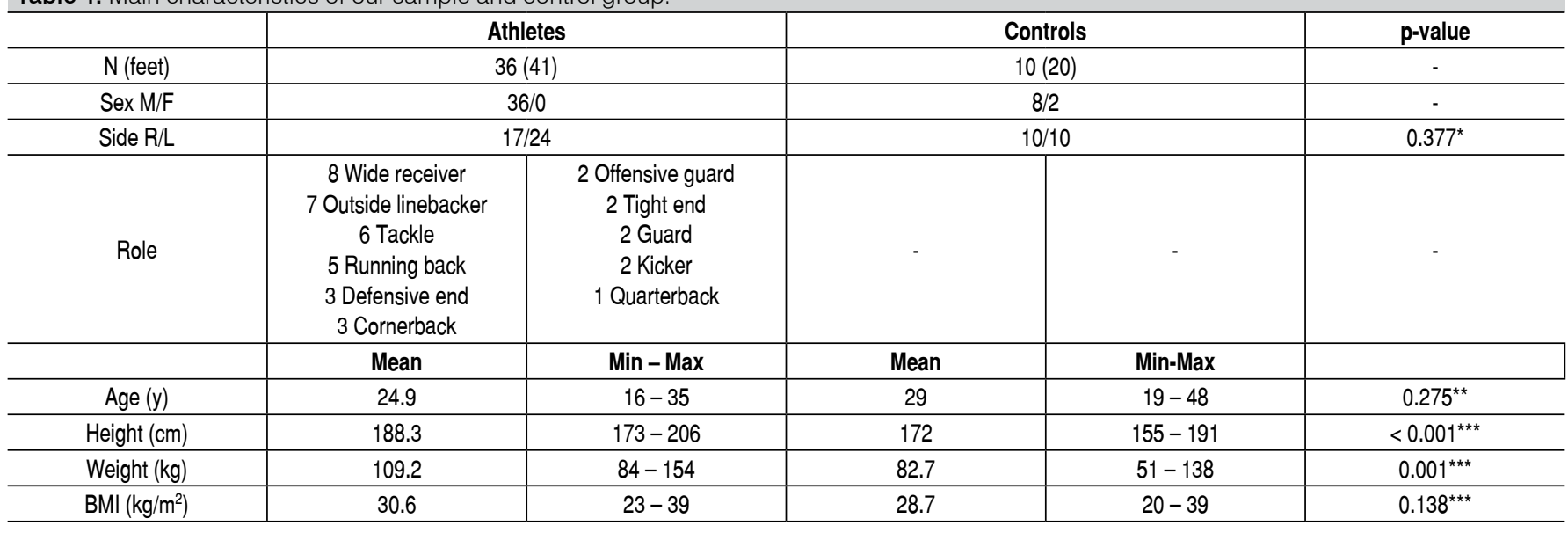

*: Fisher's exact test; **: Wilcoxon's rank-sum test; ***: Student's t test.

Groups were comparable by age, side and BMI ( $p>0.05)$. NFL athletes showed a neutrally aligned hindfoot when compared to controls (FAO mean value at $1 \%$ vs $0.5 \%$, CO at $2.3 \mathrm{~mm}$ vs 0.8 and $\mathrm{HAA}$ at $2.9^{\circ}$ vs $0.8^{\circ}$ in two groups, with all $\left.p>0.05\right)$. Inftal-Suptal and Inftal-Hor angles stood at $4.5^{\circ}$ vs $5.9^{\circ}$ (p 0.32) and $4.6^{\circ}$ vs $5.7^{\circ}$ (p 0.48) in two groups, suggesting a similar subtalar joint morphology. Conversely, NFL athletes presented a decreased medial longitudinal arch (FAA at $15^{\circ} \mathrm{vs} 18.3^{\circ}, p 0.03$ ) with smaller navicular $(38.2 \mathrm{~mm}$ vs $42.2 \mathrm{~mm}, p$ 0.03), and medial cuneiform (27 mm vs $31.3 \mathrm{~mm}, p 0.01)$ distances to the floor (Table 2).

Table 2. Comparison of values between NFL players and normally aligned controls. Normative data from literature about well-aligned feet and flatfeet have been reported as well. All variables were normally distributed; therefore, Student's t test was applied for comparison.

\begin{tabular}{|c|c|c|c|c|c|c|}
\hline \multirow[t]{2}{*}{ Variable } & $\begin{array}{c}\text { NFL } \\
(n=41)\end{array}$ & Control $(n=20)$ & \begin{tabular}{|c|} 
NFL vs Control \\
p-value*
\end{tabular} & $\begin{array}{c}\text { NBA }(n=54) \\
\text { from literature }\end{array}$ & Controls from literature & $\begin{array}{l}\text { Flatfoot from } \\
\text { literature }\end{array}$ \\
\hline & mean $(95 \% \mathrm{Cl})$ & mean $(95 \% \mathrm{Cl})$ & & & mean $(95 \% \mathrm{Cl})$ & mean $(95 \% C l)$ \\
\hline Calcaneal Offset (mm) & 2.3 (0.4 to 4.2$)$ & $0.8(-2$ to 3.8$)$ & 0.4 & $1.1(-0.5$ to 2.8$)$ & NA & NA \\
\hline $\begin{array}{l}\text { Hindfoot Alignment } \\
\text { Angle (degrees) }\end{array}$ & $2.9(0.2$ to 5.6$)$ & $1.8(-2.9$ to 6.6$)$ & 0.665 & $1.4(-0.8$ to 3.6$)$ & NA & NA \\
\hline Inftal Hor angle (degrees)* & 4.6 (2.9 to 6.2$)$ & 5.7 (3.3 to 8.1) & 0.487 & $4(2.5$ to 5.5$)$ & $\begin{array}{c}5.7(-1.0 \text { to } 12.4) \\
4.3\end{array}$ & $\begin{array}{c}15.9(10.2 \text { to } 21.6) \\
14.8\end{array}$ \\
\hline Forefoot Arch Angle (degrees)* & 15 (13.8 to 16.2$)$ & $18.3(16.4$ to 20.3$)$ & 0.03 & $15.8(14.7$ to 16.9$)$ & $18.61^{\star *}$ & $\begin{array}{c}8.89^{* *} \\
3.0(1.4 \text { to } 4.6)\end{array}$ \\
\hline Navicular-to-floor distance $(\mathrm{mm})^{*}$ & $38.2(36.3$ to 40.1$)$ & 42.2 (38.3 to 46.2$)$ & 0.03 & $38.3(36.1$ to 40.4$)$ & NA & $\begin{array}{c}19.4^{* *} \\
23(22 \text { to } 25)\end{array}$ \\
\hline
\end{tabular}

*: variables for which more than one reference value was available in literature; **: simulated weight bearing.

\section{DISCUSSION}

To the best of our knowledge, this is the first time that reference values for foot morphotypes in professional NFL players are reported in the literature using 3D WBCBCT images. Furthermore, it must be considered that historically, any available foot measurements have always relied on conventional radiographic views. This approach is highly influenced by inherent potential flaws related to the evaluation of a 2D imaging of a 3D structure. Errors in patient positioning, overlap of different structures and operator-related bias can limit the effectiveness of measurements on conventional radiographs. ${ }^{9}$ The advent of the WBCBCT allows clinicians to obtain images comparable to a traditional CT but in a physiologically-loaded condition and with a lower radiation dose. Recent studies have also documented how the foot morphotype measurements used in this study (such as the FAO, the $\mathrm{CO}$, the HAA, the Inftal-Suptal angle, the Inftal-Hor angle, the FAA, the navicular-to-floor distance and the medial cuneiform-to-floor distance) provide high intra- and inter-observer reliability. ${ }^{10,11,14,15}$

Our comparative study showed that symptomatic professional male football players within the National Football League have a normally aligned hindfoot with a more pronated forefoot when compared to healthy controls, as demonstrated by significant differences in FAA, navicular-to-floor and medial-cuneiform-to-floor distance. However, although we could not perform a formal statistical analysis including data reported by other authors, values for these measurements from 
NFL players were still far higher than historical flatfeet (Table 2). This suggests that, while their medial arch is decreased, it would probably be inappropriate to consider them as 'flatfooted' (Table 2). Secondly, when comparing our results with a previous study on NBA players in which some tendency towards varus high arched morphology was identified, we found very similar values in WBCBCT measurements (Table 2) but surprisingly this led us to a different conclusion. We believe that this discrepancy can be explained by the comparative design of this study that allowed to deem results on the basis of a control group rather than on literature data.

Unfortunately, there are only few other studies within the available literature that assess foot morphotypes in professional athletes specifically. In a study of 151 competitive triathletes, the foot typeas assessed by the Foot Posture Index and Valgus Index - did not appear as a risk factor for acute injuries of the foot and ankle, however the authors found a four-fold increase in risk of overuse injury in athletes with a supinated foot. ${ }^{16}$ According to Lopezosa-Reca et al., ${ }^{3}$ who have investigated the Foot Posture Index in 220 basketball players, the foot morphotype varied in players based on their in-game position. Guards usually had a more supinated foot, whereas centers presented a more pronated foot. However, this hypothesis has never been confirmed.

More specifically, only a small number of studies have addressed foot and ankle injuries in professional football players. In most of these, authors have investigated fractures of the fifth metatarsal affecting NFL athletes, documenting treatments, complications and return to play. ${ }^{4-6}$ Carreira and Sandilands ${ }^{6}$ analyzed risk factors and focused on foot alignment of these players, concluding that a varus alignment was more frequent in athletes who sustained a fracture of the fifth metatarsal. Raikin, Slenker and Ratigan ${ }^{17}$ investigated the foot morphotype in 20 patients (13 athletes, 7 nonathletes) presenting Jones fracture and found that the presence of a varus hindfoot alignment, assessed both clinically and radiographically, represented a predisposing factor for Jones-type metaphyseal-diaphyseal fractures and re-fractures of the fifth metatarsal. Karnovsky et al. ${ }^{5}$ recently found that NFL players with long, narrow, and straight fifth metatarsals with an adducted forefoot presented the greatest risk for fifth metatarsal fractures. This seems to corroborate the results by Rongstad et al., ${ }^{7}$ who suggested an association between metatarsus adductus and stress fractures of the base of the fourth metatarsal in athletes. Similarly, reports have linked high-arched cavus feet with higher risk of Lisfranc injuries. ${ }^{8}$ Another relevant study was a large prospective investigation on 449 military personnel in training, which showed that dynamic pes planus, pes cavus, restricted ankle dorsiflexion, and increased hindfoot inversion were associated with higher risk of lower extremity overuse injuries. ${ }^{18}$ Within the literature there is some evidence suggesting that increased participation in high-impact sports during youth would be associated with increased varus alignment of the knee at the end of growth in males, mainly due to increased frequency of intense running and cutting maneuvers. ${ }^{19}$ Furthermore, Norton et al. have reported in a non-athletic population that a compensatory valgus of the hindfoot could be expected in the setting of a varus knee. ${ }^{20}$ Whether the converse of this observation is true in professional players of high-impact sports with varus knees has yet to be investigated.

Our study has several limitations. Firstly, we could not perform any meaningful analysis about the role of players or their specific type of injury. This was essentially due to the size of the cohort. While we think that investigating the relationship between any specific injury and various foot morphotypes with WBCBCT measurements would be useful to plan dedicated prevention programs, we also believe that sharing normative data from symptomatic athletes could represent a step forward towards further analysis in specific activities. Secondly, the retrospective design and the small sample size. Thirdly, we have not performed an assessment of intra- or inter-observer agreement in this study. However, this was not among the aims of our study since previous studies have documented excellent reliability on these measures.

\section{CONCLUSION}

Professional NFL male football players seem to have a neutrally aligned hindfoot, with an overpronated forefoot (decreased medial longitudinal arch) when compared to controls. In male elite players, structured training programs have already been validated for sports injury prevention. When confirmed by further prospective and controlled investigations, the results of the current study on foot morphology may represent a starting point to guide future preventive action to reduce the rate of foot and ankle injuries in professional football. Further studies are necessary to identify groups of athletes at increased risk as well as the relationship between different foot morphotypes and specific injuries.

AUTHORS' CONTRIBUTIONS: Each author contributed individually and significantly to the development of this article. AB: Study concept and design, manuscript drafting and revision, numerical analysis and interpretation of data, final approval of the version to be published, agreement for all aspects of the work, study supervision; CCN: Study concept and design, manuscript drafting and revision, interpretation of data, final approval of the version to be published, agreement for all aspects of the work; LR: Manuscript drafting and revision, interpretation of data, final approval of the version to be published agreement for all aspects of the work; FL: Manuscript drafting and revision, final approval of the version to be published, agreement for all aspects of the work; ALGS: Manuscript drafting and revision, interpretation of data, final approval of the version to be published, agreement for all aspects of the work; MJO'M: Study concept and design, manuscript drafting and revision, interpretation of data, final approval of the version to be published, agreement for all aspects of the work, study supervision.

\section{REFERENCES}

1. Meeuwisse WH, Sellmer R, Hagel BE. Rates and Risks of Injury during Intercollegiate Basketball. Am J Sports Med. 2003;31(3):379-85.

2. Hunt KJ, Hurwit D, Robell K, Gatewood C, Botser IB, Matheson G. Incidence and Epidemiology of Foot and Ankle Injuries in Elite Collegiate Athletes. Am J Sports Med. 2017;45(2):426-33.

3. Lopezosa-Reca E, Gijon-Nogueron G, Morales-Asencio JM, Cervera-Marin JA Luque-Suarez A. Is There Any Association Between Foot Posture and Lower Limb-Related Injuries in Professional Male Basketball Players? A Cross-Sectional Study. Clin J Sport Med. 2020;30(1):46-51.

4. Tu L-A, Knapik DM, Sheehan J, Salata MJ, Voos JE. Prevalence of Jones Fracture Repair and Impact on Short-Term NFL Participation. Foot Ankle Int. 2018;39(1):6-10.

5. Karnovsky SC, Rosenbaum AJ, DeSandis B, Johnson C, Murphy CI, Warren RF, et al. Radiographic Analysis of National Football League Players' Fifth Metatarsal Morphology Relationship to Proximal Fifth Metatarsal Fracture Risk. Foot Ankle Int. 2019;40(3):318-22.
6. 6. Carreira DS, Sandilands SM. Radiographic Factors and Effect of Fifth Metatarsal Jones and Diaphyseal Stress Fractures on Participation in the NFL. Foot Ankle Int. 2013;34(4):518-22.

7. Rongstad KM, Tueting J, Rongstad M, Garrels K, Meis R. Fourth Metatarsal Base Stress Fractures in Athletes. Foot Ankle Int. 2013;34(7):962-8.

8. Podolnick JD, Donovan DS, DeBellis N, Pino A. Is pes cavus alignment associated with lisfranc injuries of the foot? Clin Orthop Relat Res. 2017;475(5):1463-9.

9. Baverel L, Brilhault J, Odri G, Boissard M, Lintz F. Influence of lower limb rotation on hindfoot alignment using a conventional two-dimensional radiographic technique. Foot Ankle Surg. 2017;23(1):44-9.

10. Lintz F, Welck M, Bernasconi A, Thornton J, Cullen NP, Singh D, et al. 3D Biometrics for Hindfoot Alignment Using Weightbearing CT. Foot Ankle Int. 2017;38(6):684-9.

11. Zhang JZ, Lintz F, Bernasconi A, Zhang S. 3D Biometrics for Hindfoot Alignment Using Weightbearing Computed Tomography. Foot Ankle Int. 2019;40(6):720-6.

12. de Cesar Netto C, Bernasconi A, Roberts L, Pontin PA, Lintz F, Saito GH, et al. Foot Alignment in Symptomatic National Basketball Association Players Using 
Weightbearing Cone Beam Computed Tomography. Orthop J Sport Med. 2019;7(2):e2325967119826081.

13. de Cesar Netto C, Schon LC, Thawait GK, Fonseca LF, Chinanuvathana A, Zbijewski WB, et al. Flexible Adult Acquired Flatfoot Deformity. J Bone Joint Surg . 2017;99(18):e98.

14. Bernasconi A, Cooper L, Lyle S, Patel S, Cullen N, Singh D, et al. Intraobserver and interobserver reliability of cone beam weightbearing semi-automatic three-dimensional measurements in symptomatic pes cavovarus. Foot Ankle Surg. 2020;26(5):564-72.

15. Lintz F, Bernasconi A, Baschet L, Fernando C, Mehdi N, de Cesar Netto C. Relationship Between Chronic Lateral Ankle Instability and Hindfoot Varus Using Weight-Bearing Cone Beam Computed Tomography. Foot Ankle Int. 2019;40(10):1175-81.

16. Burns J, Keenan A-M, Redmond A. Foot type and overuse injury in triathletes. J Am Podiatr Med Assoc. 2005;95(3):235-41.
17. Raikin SM, Slenker N, Ratigan B. The Association of a Varus Hindfoot and Fracture of the Fifth Metatarsal Metaphyseal-Diaphyseal Junction. Am J Sports Med. 2008;36(7):1367-72.

18. Kaufman KR, Brodine SK, Shaffer RA, Johnson CW, Cullison TR. The Effect of Foot Structure and Range of Motion on Musculoskeletal Overuse Injuries. Am J Sports Med. 1999;27(5):585-93.

19. Colyn W, Agricola R, Arnout N, Verhaar JAN, Bellemans J. How does lower leg alignment differ between soccer players, other athletes, and non-athletic controls? Knee Surg Sports Traumatol Arthrosc. 2016;24(11):3619-26.

20. Norton AA, Callaghan JJ, Amendola A, Phisitkul P, Wongsak S, Liu SS, et al. Correlation of Knee and Hindfoot Deformities in Advanced Knee OA: Compensatory Hindfoot Alignment and Where It Occurs. Clin Orthop Relat Res. 2015;473(1):166-74. 